\title{
Anatomia foliar de plantas micropropagadas de abacaxi
}

\author{
Sarah Brandão Santa Cruz Barboza(1), Dalva Graciano-Ribeiro(2), João Batista Teixeira( ${ }^{(3)}$, \\ Tomás Aquino Portes ${ }^{(4)}$ e Luiz Augusto Copati Souza ${ }^{(5)}$
}

\begin{abstract}
(1)Departamento Estadual de Desenvolvimento Agropecuário/Embrapa Tabuleiros Costeiros, Caixa Postal 44, CEP $44001-970$ Aracaju, SE. E-mail: sarah@cpatc.embrapa.br (2)Universidade de Brasília, Dep. de Botânica, Caixa Postal 04457, CEP 70917-970 Brasília, DF. E-mail: graciano@unb.br (3)Embrapa Recursos Genéticos e Biotecnologia, Caixa Postal 02372, CEP 70770-900 Brasília, DF. E-mail: batista@cenargen.embrapa.br (4)Universidade Federal de Goiás, Instituto de Ciências Biológicas, Dep. de Biologia Geral, Caixa Postal 131, CEP 74001-970 Goiânia, GO. E-mail: portes@icb.ufg.br (5)QE 19, Conjunto L, Casa 11, Guará II, CEP 71050-133 Brasília, DF. E-mail: luizcopati@uol.com.br
\end{abstract}

Resumo - O objetivo deste trabalho foi indicar caracteres anatômicos em folhas de plantas micropropagadas de abacaxizeiro, visando ao aperfeiçoamento do protocolo de aclimatação. Utilizaram-se plântulas micropropagadas in vitro e aclimatadas por seis e dez meses, apresentando, em média, 3,1, 50,2 e 65 g, respectivamente. A densidade estomática foi determinada na face abaxial da epiderme, nas regiões basal, mediana e apical da folha, usando o delineamento inteiramente casualizado em esquema fatorial de 2x3 (dois ambientes de cultivo e três regiões da folha), em seis repetições. A espessura da hipoderme, parênquimas aqǘfero e clorofilado foi determinada na região mediana da folha, usando-se o delineamento inteiramente casualizado com três tratamentos em quatro repetições. A estrutura básica da folha do abacaxizeiro não se modificou, entretanto, ocorreram diferenças na freqüência estomática, no espessamento da cutícula e paredes da epiderme, formato e sinuosidade das paredes das células do tecido aquíf́ero e presença de células papilosas nos diferentes ambientes de cultivo, indicando plasticidade fenotípica.

Termos para indexação: Ananas comosus, ambiente de cultivo, micropropagação, aclimatação.

\section{Leaf anatomy of micropropagated pineapple plants}

\begin{abstract}
The objective of this work was to study leaf anatomy of pineapple plants in order to improve acclimatization protocols. In vitro plantlets weighting an average of $3.1 \mathrm{~g}$ and greenhouse plantlets derived from in vitro stock material, after six and ten months of culture, weighting an average of 50.2 and $65 \mathrm{~g}$, respectively, were used. Stomatal density was determined on the abaxial epidermis, at the basal, median, and apical portions of the leaf, using a completely randomized design under 2x3 factorial (two culture environments and three leaf regions) with six replicates. Thickness of the hypodermis, aquiferous and photosynthetic parenchyma were determined at the median portion of the leaf using a totally randomized design with three treatments and four replicates. The basic structure of the pineapple leaf under in vitro conditions did not change. However, stomatal frequency, cuticular and epidermal wall thickening, shape and sinuosity of the cell walls of aquiferous parenchyma and the presence of papillary cells were verified as a result of environmental conditions during culture, indicating phenotypic plasticity.
\end{abstract}

Index terms: Ananas comosus, environment of cultivation, micropropagation, acclimatization.

\section{Introdução}

A espécie Ananas comosus pertence à família Bromeliaceae e todas as variedades de abacaxi de interesse para a fruticultura fazem parte dessa espécie (Py et al., 1984). O abacaxizeiro adulto pode ter até 70-80 folhas (Py, 1969), que podem se apresentar espinhosas, lisas ou semi-espinhosas e com espinhos apenas na extremidade.

No que se refere à anatomia foliar de Ananas comosus, em condições de campo, são descritas es- truturas anatômicas características das bromeliáceas, tais como: presença de ceras, tricomas, epiderme uniestratificada revestida por cutícula, com diâmetro maior perpendicular ao eixo da folha e presença de hipoderme (Py, 1969). Na face abaxial da epiderme, os estômatos encontram-se dispostos longitudinalmente em sulcos pequenos e paralelos (Py et al., 1984). O mesofilo apresenta tecido aqǘfero logo abaixo da face adaxial da epiderme, parênquima clorofilado ou não, onde estão os feixes vasculares, cordões de fibras isolados e canais de aeração (Py, 1969). 
Caracteres morfológicos e anatômicos, tanto vegetativos quanto reprodutivos, estão relacionados com determinadas condições ambientais, embora a relação entre esses caracteres adaptativos e condições ambientais, em muitos casos, seja difícil de estabelecer (Ehrendorf, 1973). Reeve \& Sherman (1993) definem a adaptação como uma variante fenotípica, que resulta no êxito reprodutivo entre um conjunto específico de variantes em determinado ambiente. Segundo os autores, o termo adaptação tem sido utilizado em anatomia vegetal para descrever caracteres anatômicos associados a determinadas condições ambientais.

Plântulas micropropagadas precisam de um período de aclimatação, imediatamente após a remoção do ambiente in vitro, que lhe permitirá adaptar-se às condições de cultivo em campo. A dificuldade de transição do mecanismo heterotrófico para autotrófico em plantas micropropagadas, em virtude das alterações epigenéticas anatômicas e fisiológicas, induzidas pelas condições in vitro (Campostrini \& Otoni, 1996), requer a realização de determinadas investigações, para que a aclimatação venha a ter sucesso.

O objetivo do trabalho foi indicar caracteres anatômicos em folhas de plantas micropropagadas de abacaxi, visando ao aperfeiçoamento do protocolo de aclimatação.

\section{Material e Métodos}

O trabalho foi desenvolvido no Laboratório de Anatomia Vegetal da Universidade de Brasília. O cultivo in vitro e a aclimatação das plântulas foram realizados na Embrapa Recursos Genéticos e Biotecnologia.

Na avaliação do material in vitro, usaram-se plântulas de abacaxi, Ananas comosus (L.) Merr., cultivar Pérola, com 3,1 g de peso médio (Figura 1 A), alongadas, por dois meses, em meio de cultivo MS gelificado, sem adição de fitorreguladores, em sala de crescimento com intensidade luminosa de $30 \mu \mathrm{mol} \mathrm{m}{ }^{-2} \mathrm{~s}^{-1}$, temperatura de $25 \pm 2^{\circ} \mathrm{C}$ e fotoperíodo de 16 horas. Em casa de vegetação, as plantas foram aclimatadas por seis e dez meses, em ambiente com sombreamento de $60 \%$, temperatura média diária de $27,2^{\circ} \mathrm{C}$ e $65,5 \%$ de umidade relativa média, e apresentavam, em média, 50,2 e 65,0 g de peso, respectivamente.

A análise anatômica foi efetuada na quarta e quinta folha, do ápice para a base, no material in vitro e em aclimatação, respectivamente. Os cortes foram realizados no terço mediano das folhas e confeccionadas qua- tro lâminas por folha, num total de 16 lâminas por terço da folha por ambiente de cultivo.

No preparo das lâminas permanentes, os segmentos de cada região da folha foram fixados em FAA 37\% (formaldeído ácido acético glacial) e etanol 70\% por 48 horas, transferidos para etanol 70\%, desidratados em uma série etílica (Johansen, 1940) e incluídos em parafina. Secções transversais de 8 e $10 \mu \mathrm{m}$ foram obtidas em micrótomo e, depois da remoção da parafina, submetidas à dupla coloração com safranina e fast-green.

A densidade estomática foi determinada nas regiões basal, mediana e apical da folha, utilizando-se o delineamento inteiramente casualizado em esquema fatorial de 2x3 (dois ambientes de cultivo e três regiões da folha), em seis repetições, empregando-se a técnica de Labouriau et al. (1961), com auxílio de fotomicroscópio equipado com câmara clara. Na confecção das lâminas, foram utilizadas películas de esmalte com impressão das faces adaxial e abaxial da folha nas regiões onde foram feitas as contagens.

A espessura dos tecidos do mesofilo foi avaliada utilizando-se o delineamento inteiramente casualizado com três tratamentos (hipoderme, parênquima aqüífero e parênquima clorofilado) em quatro repetições para cada ambiente de cultivo. Para comparar as razões de espessura entre parênquima aclorofilado e parênquima clorofilado das folhas in vitro com as de casa de vegetação, considerou-se a hipoderme e o parênquima aqüífero como parênquima aclorofilado. Os dados foram submetidos à análise de variância e as médias comparadas pelo teste de Duncan a 5\% de probabilidade.

\section{Resultados e Discussão}

Nas folhas in vitro, observa-se cutícula pouco desenvolvida nas faces adaxial e abaxial da epiderme (Figura 1 B, C e D). As folhas de plantas com seis e dez meses em aclimatação apresentaram epiderme recoberta por cutícula em toda sua extensão, cujo espessamento é variável (Figura 2 A, H e I e Figura 3 A, D e E, respectivamente).

O padrão de espessamento da parede das células epidérmicas é determinado pelo grau de exposição ao sol (Withner et al., 1974) e é considerado uma característica de ambiente ensolarado. As folhas das plantas de abacaxi, desenvolvidas em casa de vegetação, onde $60 \%$ da luz solar é interceptada, apresentaram células epidérmicas adaxiais com espessamento da parede entre 8 e $10 \mu \mathrm{m}$ (Figura $2 \mathrm{H}$ e Figura 3 D) na região do 

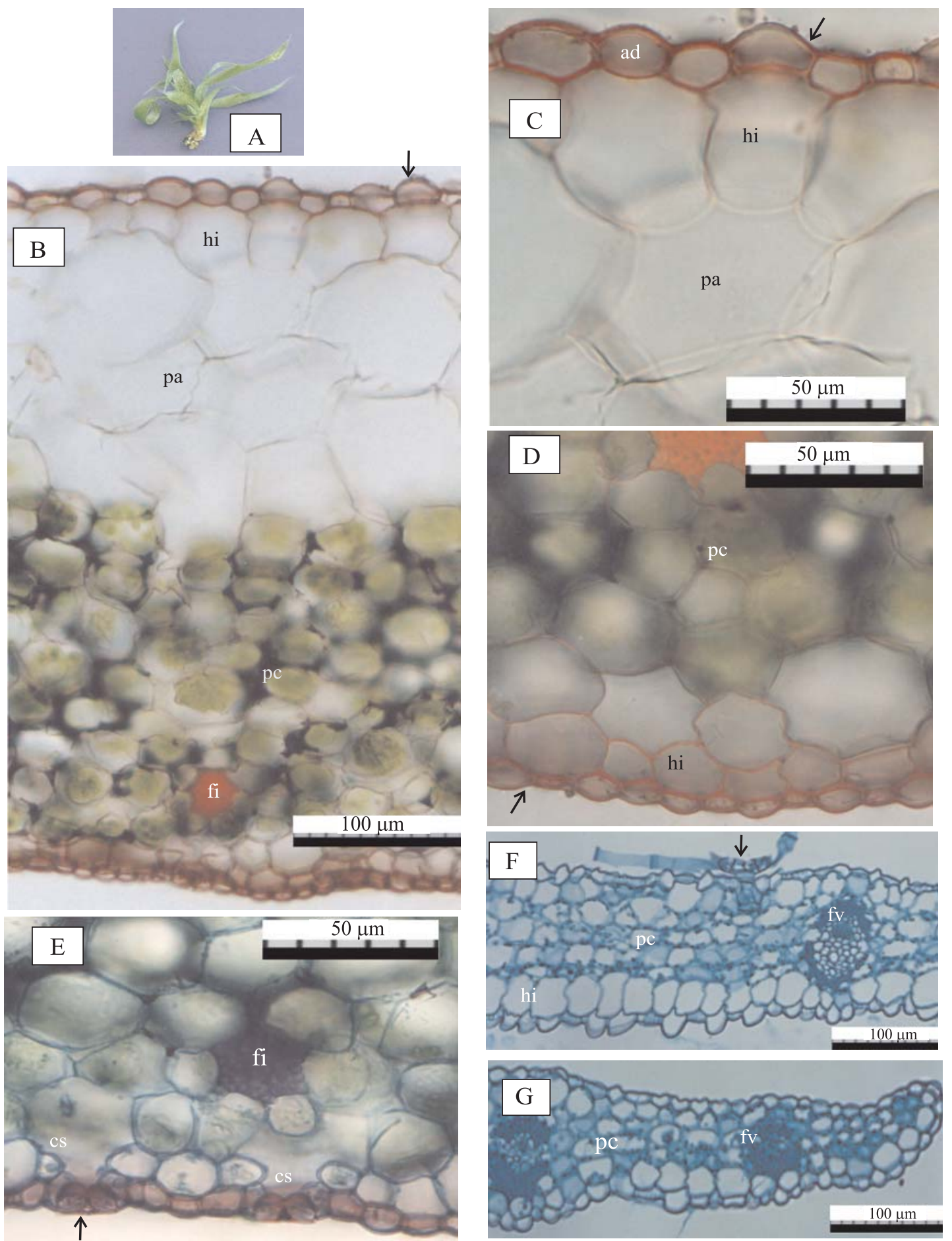

Figura 1. Cortes transversais da folha in vitro do abacaxi cv. Pérola. A:plântula micropropagada; B: mesofilo diferenciado na região do eixo central mostrando cutícula delgada ( $\downarrow)$, hipoderme (hi), parênquimas aqüífero (pa) e clorofilado (pc) e fibras (fi); C: células epidérmicas adaxiais de paredes finas (ad), células papilosas $(\swarrow)$, parênquimas aqüífero (pa); D: epiderme abaxial com cutícula delgada $(\nearrow)$, hipoderme (hi) e parênquima clorofilado (pc); E: face abaxial mostrando estômato ( $\uparrow$ ); câmara subestomárica (cs) e fibras (fi); F: tricoma $(\downarrow)$; hipoderme (hi) e feixe vascular (fv); parênquima clorofilado (pc); G: mesofilo homogêneo na região do bordo foliar; parênquima clorofilado (pc); e feixe vascular (fv). 

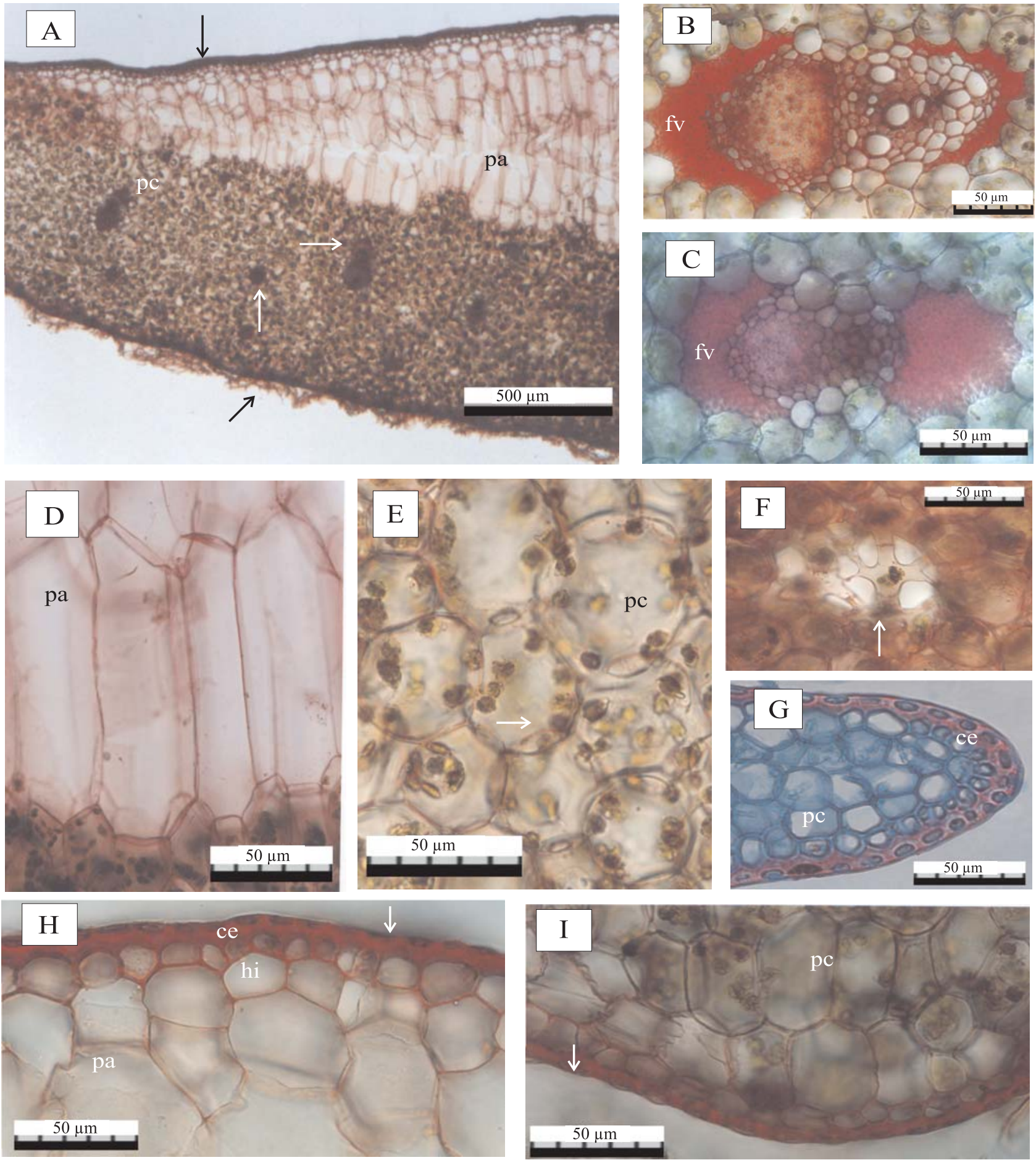

Figura 2. Cortes transversais em folha de abacaxizeiro micropropagado, aos seis meses em casa de vegetação. A: mesofilo diferenciado na região do eixo central; epiderme adaxial recoberta com cutícula $(\downarrow)$ ), parênquima aqüífero (pa) e clorofilado (pc), feixe vascular $(\rightarrow$ ), fibras $(\uparrow)$ e epiderme abaxial $(\nearrow)$; B: feixe vascular na região do eixo central (fv); C: feixe vascular na região do bordo foliar (fv) e tecido clorofilado (tc); D: células do parênquima aqüífero com paredes planas (pa); E: parênquima clorofilado (pc) mostrando cloroplastos $(\rightarrow)$; F: aerênquima ( $\uparrow$ ); G: bordo foliar com mesofilo homogêneo; parênquima clorofilado (pc), células epidérmicas com paredes bastante espessadas (ce); H: células epidérmicas adaxiais com paredes espessadas (ce), lúmen reduzido ( $\downarrow$ ), hipoderme (hi), parênquima aqüífero (pa); I: parênquima clorofilado (pc); epiderme adaxial recoberta com cutícula $(\downarrow)$. 
eixo central, e 10 e $12 \mathrm{~mm}$ na região do bordo foliar (Figura $2 \mathrm{G}$ ). Na face abaxial, o espessamento foi menor (Figura 2 I e Figura 3 E). O aumento da espessura da parede e cutícula é uma das respostas das plantas a ambientes secos (Juniper \& Jeffree, 1983), no entanto, plantas desenvolvidas sob condições de grande umida-
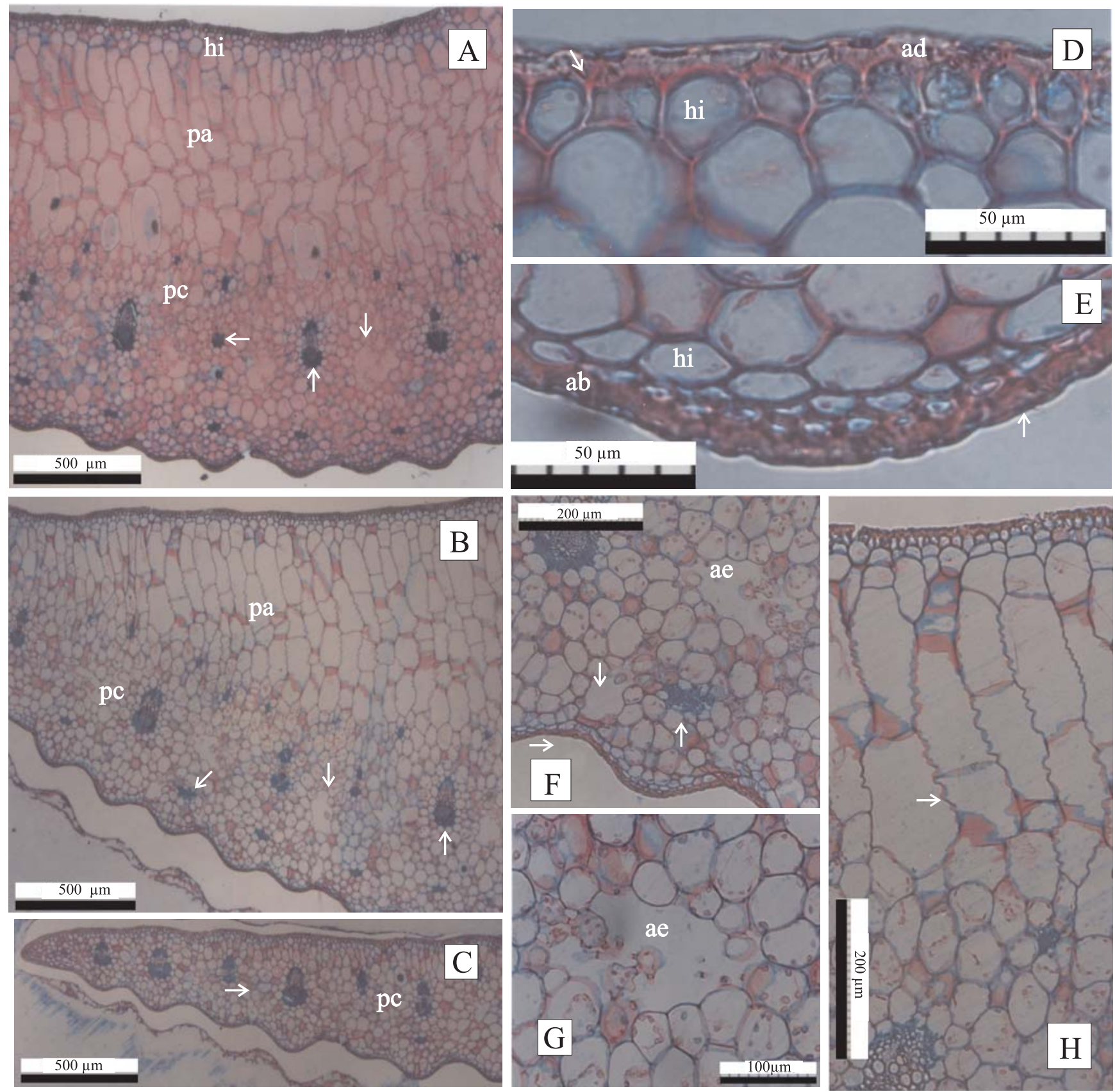

Figura 3. Cortes transversais em folha de abacaxizeiro, cv. Pérola, aos dez meses em casa de vegetação. A:mesofilo diferenciado na região do eixo central; hipoderme (hi), parênquima aqüífero (pa), parênquima clorofilado (pc), fibras $(\leftarrow)$ ), feixe vascular $(\uparrow)$ e aerênquima ( $\downarrow$ ); B: mesofilo diferenciado na região eixo bordo; parênquimas aqüífero (pa) e clorofilado (pc), fibras ( $\swarrow$ ), aerênquima $(\downarrow)$ e feixe vascular $(\uparrow)$; C: mesofilo homogêneo na região do bordo foliar; parênquima clorofilado (pc) e feixe vascular $(\rightarrow)$; D e E: epiderme adaxial (ad) e abaxial (ab), respectivamente, mostrando cutícula ( $\downarrow$ e $\uparrow$ ) e hipoderme (hi); nota-se maior espessamento das paredes da epiderme adaxial; F: aerênquima (ae), cavidade subestomática ( $\downarrow$ ) e estômato ( $\rightarrow$ ); G: aerênquima (ae); H: células do parênquima aqüífero com sinuosidades nas paredes $(\rightarrow)$. 
de também podem desenvolver cutícula mais espessa que aquelas desenvolvidas normalmente (Elias, 2001).

As folhas in vitro apresentaram paredes periclinais externas curvas ou convexas nas faces adaxial (Figura 1 B e C) e abaxial (Figura 1 D) e células papilosas (Figura 1 C). As células epidérmicas das folhas em aclimatação apresentam paredes periclinais externas retas ou quase retas (Figura 2 H e Figura 3 D). Em vista paradérmica, a epiderme das folhas in vitro e em casa de vegetação apresentou células com paredes anticlinais de formato mais ou menos retangular com paredes sinuosas (Figura 4 A e C).

A sinuosidade das paredes anticlinais das células epidérmicas pode ser atribuída às condições ambientais, sendo mais acentuada em plantas que se desenvolvem à sombra (Wilkinson, 1979) ou em ambientes úmidos (Gomes, 1992). A curvatura das células epidérmicas aumenta a eficiência das folhas para a captação de luz e a densidade do fluxo laminoso no interior da lâmina foliar (Bone et al., 1985). Vieira \& Machado (1992) atribuem essa mesma função às células papilosas da face abaxial das folhas de sombra e de ambiente intermediário de Bauhinia radiata. A baixa irradiância, $30 \mu \mathrm{mol} \mathrm{m}{ }^{-2} \mathrm{~s}^{-1}$, e a alta umidade relativa do ambiente in vitro são fatores que, possivelmente, podem estar relacionados com a presença de células papilosas nas folhas de abacaxizeiro in vitro.

Tricomas glandulares multicelulares estão presentes nas faces adaxial e abaxial da epiderme das folhas nos dois ambientes estudados (Figura $1 \mathrm{~F}$ ). Esses resultados estão de acordo com os obtidos por Py et al. (1984) em folhas de abacaxizeiro em condições de campo. $O$ poder de reflexão que tem uma folha de abacaxizeiro recoberta de tricomas pode ser até $27 \%$ superior ao de folhas das quais os tricomas tenham sido eliminados (Py, 1969). Tais estruturas podem representar uma adaptação morfológica que atua de modo a restringir a perda de água pelas folhas, por meio da regulação da temperatura, pela reflexão da luz que chega às folhas, e pode, ainda, secretar substâncias que protegem as folhas contra parasitas e predadores (Larcher, 2000). A freqüência de tricomas pode aumentar com a intensidade da luz solar, exposição ao vento, umidade do solo, do ar e altitude (Ellis, 1976).

As folhas de abacaxizeiro são hipoestomáticas, independentemente do ambiente de cultivo (Figura 4 A e C). Os estômatos estão distribuídos em faixas paralelas por toda extensão da face abaxial (Figura 1 E, Figura 3 F e Figura 4 B e D), apresentando câmara subestomática (Figura 1 E e Figura $4 \mathrm{E} \mathrm{e} \mathrm{F}$ ). As folhas de plantas in vitro apresentaram, em média, 54 estômatos $\mathrm{mm}^{-2}$, valor estatisticamente inferior ao observado em folhas de casa de vegetação, que foi de 62 estômatos $\mathrm{mm}^{-2}$ (Tabela 1). A densidade estomática foi superior no terço médio das folhas, independentemente do ambiente de cultivo (Tabela 1).

Plantas adultas de abacaxizeiro, em condições de campo, apresentam 70 a 85 estômatos $\mathrm{mm}^{-2}$ na face abaxial das folhas (Py, 1969). Essa densidade estomática pode ser considerada baixa quando comparada com espécies com características xeromorfas. Rezende (1987), trabalhando com Bauhinia forficata L., espécie heliófila presente em bordas de mata, com caracteres foliares tipicamente xeromorfos, observou freqüência estomática de 400 e 906 estômatos $\mathrm{mm}^{-2}$ nas faces adaxial e abaxial, respectivamente; densidade de 538 estômatos $\mathrm{mm}^{-2} \mathrm{na}$ face adaxial e 881 estômatos $\mathrm{mm}^{-2}$ na face abaxial foram obtidos por Elias (2001) em plantas de Solanum lycocarpum, espécie encontrada no Cerrado.

Em espécies cultivadas não adaptadas a ambientes secos, como Zea mays, foi constatado que a deficiência hídrica pode promover o aumento da freqüência estomática (Ristic \& Cass, 1991). Em Paspalum vaginatum, gramínea com características xeromorfas, a freqüência estomática foi negativamente correlacionada com a precipitação (Bastos et al., 1993). A freqüência estomática observada neste trabalho revela consonância com os ambientes estudados, tendo em vista que a baixa atividade autotrófica e baixa eficiência estomática impostas pelas condições in vitro estariam relacionadas com a diminuição do número de estômatos por unidade de área.

In vitro e em casa de vegetação, constata-se a presença de hipoderme em ambas as faces da epiderme (Figura 1 C e D, Figura 2 H e Figura 3 D). A hipoderme é considerada a estrutura mais comum para o armazenamento de água, estando presente em espécies epífitas de Gesneriaceae, Eriaceae, Clusiaceae, Arabiaceae e Bromeliaceae (Madison, 1977). De acordo com este autor, além de armazenar água, a hipoderme exerce papel importante na economia de calor, especialmente nas epífitas com metabolismo ácido crassuláceo. Espírito Santo \& Pugialli (1998) atribuem a sua duplicação à maior exposição à luz. A presença da hipoderme nas folhas desenvolvidas in vitro não poderia ser atribuída a nenhum destes fatores, tendo em vista que a planta in vitro está submetida a condições de baixa luminosidade e alta umidade. 

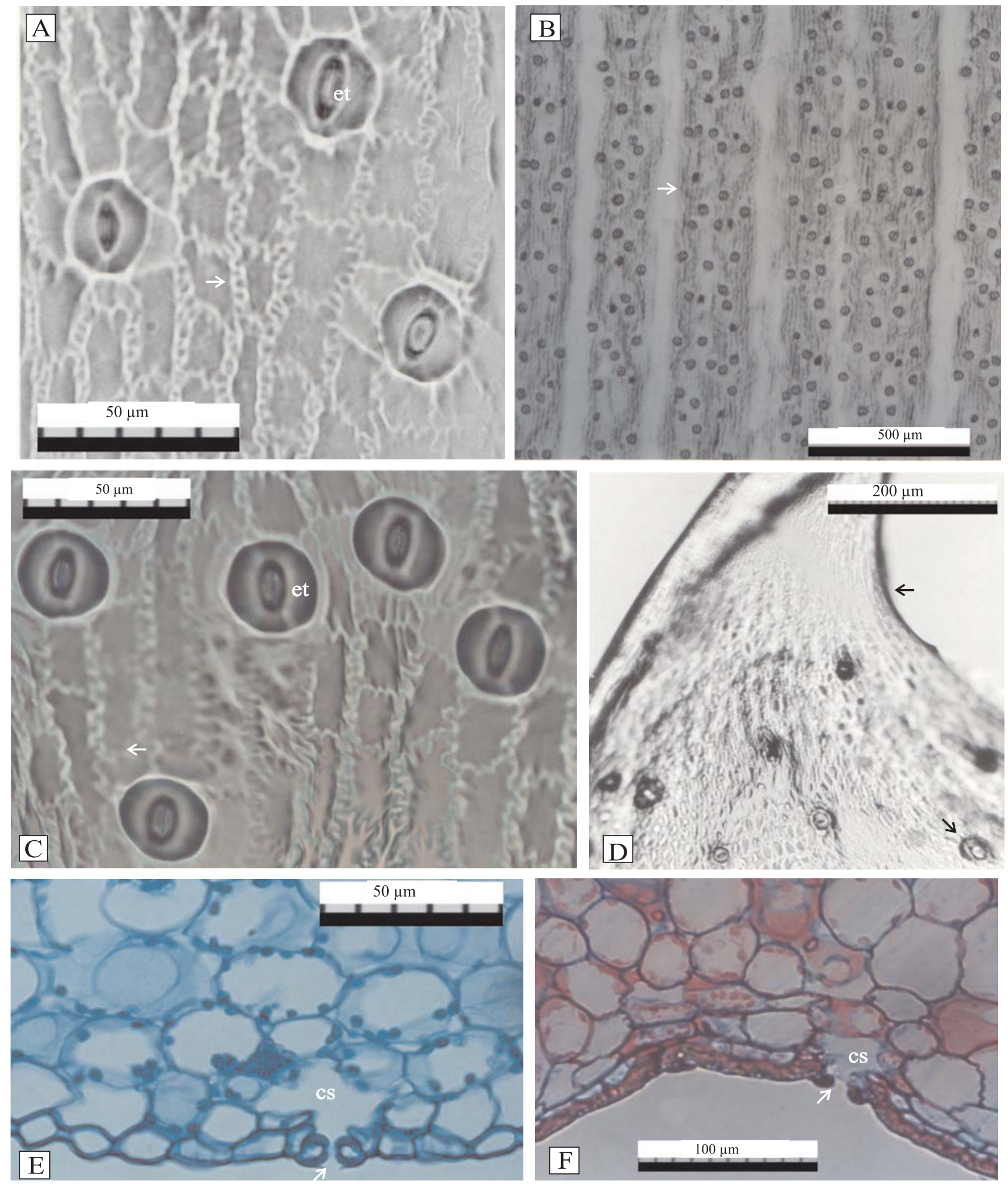

Figura 4. Vista frontal da epiderme abaxial (A, B, C e D) e cortes tranversais (E, F) em folhas de abacaxi cv. Pérola in vitro e casa de vegetação; A e C: estômatos (et) e células epidérmicas com paredes sinuosas $(\rightarrow$ ) em folhas in vitro e casa de vegetação, respectivamente; B: estômatos distribuídos em fileiras paralelas $(\rightarrow)$; D: estômatos ( $(\searrow$ ) localizados próximo aos espinhos; E e F: câmara subestomática (cs) e estômatos ( $\pi$ ) em folhas in vitro e casa de vegetação, respectivamente. 
Em secções transversais, a lâmina foliar de plantas micropropagadas de abacaxi, in vitro e em casa de vegetação, apresenta mesofilo dorsiventral na região do eixo central da folha (Figura $1 \mathrm{~B}$, Figura $2 \mathrm{~A}$ e Figura $3 \mathrm{~A}$ ) e homogêneo na região do bordo foliar (Figura 1 G, Figura 2 G e Figura 3 C). In vitro, a lâmina foliar mostra um parênquima aqǘfero constituído por células grandes de formato arredondado, paredes delgadas, planas ou com leves ondulações (Figura 1 B e C). As células do parênquima clorofilado apresentam formato arredondado (Figura 1 B, D e E), observando-se os cloroplastos distribuídos centrifugamente por toda a parede da célula (Figura $1 \mathrm{~F}$ e Figura 4 E).

Nas folhas de plantas em aclimatação, na face adaxial, observa-se, logo abaixo da hipoderme, um parênquima aqüífero constituído de células grandes, com paredes delgadas e planas (Figura $2 \mathrm{~A}$ e D); na região do eixo central, observam-se três ou quatro estratos de células (Figura 2 A). Da região do eixo central da folha em direção ao bordo foliar, ocorre diminuição do tamanho e número de camadas de células do parênquima aqüífero, até se observar um mesofilo homogêneo (parênquima clorofilado) na região do bordo foliar (Figura 2 A e Figura 3 A, B e C).

O mesofilo das primeiras folhas a serem formadas numa planta é menos diferenciado do que o das folhas subseqüentes (Esau, 1974). Foi possível observar, nas folhas de abacaxizeiro, a diferenciação bem marcante entre os parênquimas aqüífero e clorofilado in vitro e em aclimatação, embora o formato das células em paliçada tenha sido observado apenas no parênquima aqüífero de plantas em casa de vegetação. A sinuosidade das paredes do tecido aqüífero, relatada em plantas adultas em condições de campo (Py, 1969), foi observada apenas nas folhas de plantas com dez meses em aclimatação (Figura $3 \mathrm{H}$ ), o que pode representar caráter adaptativo ou resposta às condições de suprimento de água.

Tabela 1. Número de estômatos $\mathrm{mm}^{-2}$ na face abaxial de folhas de abacaxizeiro in vitro e aos seis meses em casa de vegetação $^{(1)}$.

\begin{tabular}{lcc}
\hline Região da folha & \multicolumn{2}{c}{ Ambiente de cultivo } \\
\cline { 2 - 3 } & In vitro & Casa de vegetação \\
\hline Basal & $46 \mathrm{~b}$ & $39 \mathrm{~b}$ \\
Mediana & $67 \mathrm{a}$ & $77 \mathrm{a}$ \\
Apical & $50 \mathrm{~b}$ & $74 \mathrm{a}$ \\
\hline Total & $54 \mathrm{~B}$ & $62 \mathrm{~A}$ \\
\hline
\end{tabular}

(1)Médias seguidas de mesma letra, minúscula na coluna e maiúscula na linha, não diferem entre si pelo teste de Duncan a 5\% de probabilidade.
Em cada ambiente de cultivo, a espessura do parênquima aqüífero e do parênquima clorofilado, na região do eixo central da folha, não diferiram entre si, assim como a razão entre tecido aclorofilado (hipoderme + parênquima aqüífero) e parênquima clorofilado (Tabela 2). Nesta região da folha, o parênquima aqüífero ocupa, em ambos os ambientes, em torno de $50 \%$ do mesofilo (Figura 1 B, Figura 2 A e Figura 3 A) e, o exame deles pode indicar o estado hídrico da planta (Py, 1969). Segundo o autor, quando em condições de deficiência hídrica, as células suprem as necessidades de água da planta, contraindo-se e recuperando-se posteriormente, quando em condições adequadas de suprimento de água.

A presença da hipoderme e do parênquima aqüífero nas folhas in vitro pode ser correlacionada com o alto índice de sobrevivência de plântulas de abacaxi, quando transferidas para casa de vegetação. Embora com alta taxa de sobrevivência, a muda micropropagada não apresenta bom crescimento, principalmente nos primeiros dois meses em aclimatação. Estudos visando a obter informações sobre as funções fisiológicas da hipoderme e do parênquima aqüífero, principalmente na fase de transição da planta in vitro para ex vitro, poderiam contribuir para melhoria do crescimento da muda e redução do tempo em casa de vegetação.

In vitro e em casa de vegetação, os feixes vasculares apresentam tamanho variado com grande quantidade de fibras junto ao floema e xilema (Figura $1 \mathrm{~F}$ e $\mathrm{G}$ e Figura 2 B e C), estando em maior intensidade na região do bordo foliar (Figura $1 \mathrm{G}$ e Figura $2 \mathrm{C}$ ). Os feixes vasculares estão, regularmente, distribuídos no parênquima clorofiliano na região do eixo central da folha (Figura 2 A e Figura 3 A e B) e bordo foliar (Figura $3 \mathrm{C}$ ).

Tabela 2. Espessura dos tecidos do mesofilo e razão entre espessura de parênquima aclorofilado (aqǘfero + hipoderme) e espessura de parênquima clorofilado na região do eixo central de folhas de abacaxizeiro in vitro e aos seis meses em casa de vegetação ${ }^{(1)}$.

\begin{tabular}{lcc}
\hline Tecido & \multicolumn{2}{c}{ Espessura $(\mu \mathrm{m})$} \\
\cline { 2 - 3 } & In vitro & Casa de vegetação \\
\hline Hipoderme & $42 \mathrm{~b}$ & $41 \mathrm{~b}$ \\
Parênquima aqüífero & $204 \mathrm{a}$ & $661 \mathrm{a}$ \\
Parênquima clorofilado & $195 \mathrm{a}$ & $636 \mathrm{a}$ \\
Parênquima aclorofilado/clorofilado & $1,13 \mathrm{~A}$ & $1,02 \mathrm{~A}$ \\
\hline
\end{tabular}

(1)Médias seguidas de mesma letra, minúscula na coluna e maiúscula na linha, não diferem entre si pelo teste de Duncan a 5\% de probabilidade. 
Nas folhas desenvolvidas in vitro e em casa de vegetação, observam-se cordões de fibra distribuídos por todo parênquima clorofilado, ligeiramente abaixo e entre os feixes, e também próximo ao parênquima aqüífero (Figura $1 \mathrm{~B}$ e E, Figura 2 A e Figura 3 A e B). Os cordões de fibra são típicos da planta de abacaxi e de algumas espécies vizinhas da família das bromeliáceas (Py, 1969), sendo formadas por células esclerenquimáticas. A presença de fibras no mesofilo tem sido relacionada à exposição dos indivíduos a uma luminosidade intensa e a ambientes secos (Pyykkö, 1966). Neste trabalho, a presença de fibras não mostrou correlação com intensidade luminosa e umidade, estando, provavelmente, relacionada ao suporte mecânico.

Em folhas de ambos os ambientes avaliados, observaram-se cavidades aeríferas intercaladas aos feixes vasculares (Figura 2 F e Figura 3 A, B, F e G). Para Henslo (1911), todos os grupos de monocotiledôneas que apresentam canais de ar nas folhas teriam um ancestral aquático comum. Em plantas aquáticas, esses espaços podem ser bem desenvolvidos, formando um sistema de ligação por toda a planta (Cutter, 1986). O desenvolvimento de aerênquima é uma resposta à escassez de oxigênio e atua como um reservatório de gás que oxigena os órgãos subterrâneos, sendo esta a principal função dos canais de aeração nas espécies hidrófitas (Aliscioni, 2000). Em plantas terrestres como o abacaxizeiro, esses canais de aeração parecem desempenhar função reguladora nas trocas gasosas entre a planta e o meio.

\section{Conclusões}

1. Folhas de mudas de abacaxizeiro micropropagadas in vitro e em casa de vegetação apresentam estruturas básicas semelhantes, tais como presença de fibras, hipoderme, parênquima aqǘfero, parênquima clorofilado e cavidades aeríferas.

2. As variações estruturais como freqüência estomática, espessamento da cutícula e parede da epiderme, formato e sinuosidade das paredes das células do parênquima aqüífero e presença de células papilosas são resultantes das condições nos ambientes in vitro e casa de vegetação, demonstrando plasticidade fenotípica.

\section{Referências}

ALISCIONI, S.S. Anatomía ecológica de algunas especies del género Paspalum (Poaceae, Panicoideae, Paniceae). Darwiniana, v.38, p.187-207, 2000.

BASTOS, E.O.; PERAZZOLO, M.; BATISTA, J.M.R. Variação do número de estômatos e micropelos em Paspalum vaginatum em relação às condições abióticas numa marisma do estuário da Lagoa dos Patos, RS, Brasil. Acta Botanica Brasilica, v.6, p.105-117, 1993.

BONE, R.A.; LEE, D.W.; NORMAN, J.M. Epidermal cells functioning as lenses in leaves of tropical rain-forest shade plants. Applied Optics, v.24, p.1408-1412, 1985.

CAMPOSTRINI, E.; OTONI, W.C. Aclimatização de plantas: abordagens recentes. Brasília: Embrapa-CNPH, 1996. 12p. (ABCTP notícias, 25).

CUTTER, E.G. Anatomia vegetal: órgãos - experimentos e interpretação. 1.ed. São Paulo: Roca, 1986. v.2, 335p.

EHRENDORFER, F. Adaptive significance of major taxonomic characters and morphological trends in angiosperms. In: HEYWOOD, V.H. (Ed.). Taxonomy and ecology. London: Academic Press, 1973. p.317-327.

ELIAS, S.R. de M. Anatomia foliar, deficiência hídrica e fenologia em Solanum lycocarpum St. Hill. (Solanaceae). 2001. 98p. Dissertação (Mestrado) - Universidade Federal de Goiás, Goiânia.

ELLIS, R.P. A procedure for standardizing comparative leaf anatomy in the Poaceae. I. The leaf blade as viewed in transverse section. Bothalia, v.12, p.65-109, 1976.

ESAU, K. Anatomia das plantas com sementes. São Paulo: E. Blucher, 1974. 293p.

ESPÍRITO SANTO, A. do; PUGIALLI, H.R.L. Estudo da plasticidade anatômica foliar de Stromanthe thalia (Vell.) J.M.A. Braga (Marantaceae) em dois ambientes de Mata Atlântica. Rodriguésia, v.50, p.107-122, 1998.

GOMES, D.M.S. Anatomia foliar de Gomidesia spectabilis (DC) Berg e G. nitida (Vell) Legr. (Myrtaceae). 1992. 102p. Dissertação (Mestrado) - Universidade Federal do Rio de Janeiro, Rio de Janeiro.

HENSLO, G. The origin of monocotyledons from dicotyledons, through self-adaptation to a moist, or aquatic habit. Annals of Botany, v.25, p.717-744, 1911.

JOHANSEN, D.A. Plant microtechnique. New York: McGrawHill Book, 1940. 528p.

JUNIPER, B.E.; JEFFREE, C.E. Plant surfaces. London: E. Arnold, 1983. 93p.

LABORIAU, L.C.; OLIVEIRA, J.C. de; LABORIAU, F.M.L.S. Transpiração de Schizolobium parahyba (Vell.) Velloso. Anais da Academia Brasileira de Ciências, v.33, p.248-251, 1961.

LARCHER, W. Ecofisiologia vegetal. São Carlos: Rima Artes e Textos, 2000. 531p. 
MADISON, M. Vascular epiphytes: their systematic occurrence and salient features. Selbyana, v.2, p.1-13, 1977.

PY, C. La piña tropical. Barcelona: Blume, 1969. 278p.

PY, C.; LACOEUILHE, J.J.; TEISSON, C. L’ananas, sa culture, ses produits. Paris: G. P. Maisonneuve \& Larose, 1984. 562p.

PYYKKÖ, M. The leaf anatomy of East Patagonian xeromorphic plants. Annales Botanici Fennici, v.3, p.453-622, 1966.

REEVE, H.K.; SHERMAN, P.W. Adaptation and the goals of evolutionary research. Quarterly Review of Biology, v.68, p.1-32, 1993.

REZENDE, M.H. Anatomia comparada de duas espécies de Bauhinia L. (Leguminoseae - Caesalpinoideae). 1987. 109p. Dissertação (Mestrado) - Universidade Estadual Júlio Mesquita Filho, São Paulo.
RISTIC, Z.; CASS, D.D. Leaf anatomy of Zea mays L. in response to water shortage and high temperature: a comparison of droughtresistant and drought-sensitive lines. Botanical Gazette, v.152, p.173-185, 1991.

VIEIRA, R.C.; MACHADO, R.D. Superfície foliar de Bauhinia radiata Vell. em dois ambientes. Hoehnea, v.19, p.111-116, 1992.

WILKINSON, H.P. The plant surface (mainly leaf). In: METCALFE, C.R.; CHALK, L. (Ed.). Anatomy of the dicotyledons. $2^{\text {nd }}$ ed. Oxford: Clarendon Press, 1979. v.1, p.97-162.

WITHNER, C.L.; NELSON, P.K.; WEJKSNORA, P.J. The anatomy of orchids. In: WITHNER, C.L. (Ed.). The orchids: scientific studies. New York: J. Wiley, 1974. p.267-334.

Recebido em 5 de agosto de 2004 e aprovado em 8 de julho de 2005 